J. Lake Sci.(湖泊科学), 2008, 20(2): 228-234

http://www.jlakes.org. E-mail: jlakes@niglas.ac.cn

(C)2008 by Journal of Lake Sciences

\title{
背角无齿蚌滤食对营养盐和浮游藻类结构影响的模拟*
}

\author{
杨东妹 ${ }^{1,2}$, 陈宇炜 ${ }^{1}$, 刘正文 ${ }^{1}$, 吴庆龙 ${ }^{1 * *}$ \\ (1: 中国科学院南京地理与湖泊研究所, 南京 210008) \\ (2: 中国科学院研究生院, 北京 100049)
}

摘 要: 利用微型生态系统研究背角无齿蚌(Anodonta woodiana)高密度养殖情况下对微型生态系统水柱中不同形态氮磷浓度 和浮游藻类群落结构的影响, 结果显示蚌的高强度滤食: (1)减少微型生态系统中悬浮态氮的含量, 明显增加了水柱中的溶解 性氮、磷含量，但是对总氮、总磷和正磷酸盐含量没有显著影响; (2)显著减少所有浮游藻类的数量和生物量，提高水体透明度， 同时迅速改变微型生态系统中浮游藻类的群落结构, 降低了微囊藻等蓝藻的数量及其所占的相对百分比, 而绿藻所占的比例 迅速上升; (3)导致微型生态系统的生态结构发生了显著变化, 上行效应(Bottom-up effects)在浮游藻类与营养盐的关系方面发 生了变化, 实验组水柱中氮、磷含量与浮游藻类的相关关系显著降低; (4)并不能有效降低微型生态系统的富营养水平.

关键词: 微型生态系统; 背角无齿蚌; 氮; 磷; 浮游藻类; 生物调控

\section{Top-down effects of Anodonta woodiana on nutrient concentration \& phytoplankton community composition in a microcosm ecosystem}

\author{
YANG Dongmei ${ }^{1,2}$, CHEN Yuwei ${ }^{1}$, LIU Zhengwen ${ }^{1} \&$ WU Qinglong ${ }^{1}$ \\ (1: Nanjing Institute of Geography and Limnology, Chinese Academy of Sciences, Nanjing 210008, P.R. China) \\ (2: Graduate School of Chinese Academy of Sciences, Beijing 100049, P.R.China)
}

Abstract: Microcosm experiments were conducted to study the impacts of intensive cultivation of Anodonta woodiana on nutrient concentration (different forms of phosphorus and nitrogen) and phytoplankton community structure. The results showed that the bivalve increased the concentration of total soluble phosphorus, total soluble nitrogen, and water transparency, but had decreased the concentration of particle nitrogen. There were, however, no significant influences on the total phosphorus, total nitrogen, and ortho-phosphorus. The intense filter feeding of Anodonta woodiana strongly restrained the growth of phytoplankton. Apparent changes of phytoplankton community structure were observed. The percentage of Cyanobacteria sp. decreased greatly, while the percentage of Chlorophyte sp. increased during the first 30 days' experiment. There was a slight increase of Bacillariophyte sp. percentage, but no change of Cryptophyte sp. The bottom-up effect of nutrient (i.e. phosphorus, nitrogen) on phytoplankton, which was significant in the control (no feeding), had been shifted to the strong top-down effects based on the Spearman correlation analysis between nutrient concentration and biomass of phytoplankton. With the decreasing of phytoplankton abundance, a sort of filamentous alga, Ulothrix sp., and some attached algae had gradually inhabited in the microcosm system. This study suggested that the use of intensive bivalve for bio-manipulation may not be a good method to changenge the eutrophication status significantly, although its suppression of phytoplankton and improving of water transparency were observed in the microcosms.

Keywords: Microcosm; bivalve; phosphorus; nitrogen; phytoplankton; bio-manipulation

以藻类水华, 尤其是蓝藻水华为主要特征的湖泊富营养化成为全球环境问题之一 ${ }^{[1]}$, 在控制湖泊外 来氮、磷等营养物质的基础上，利用生物调控等技术措施来控制蓝藻水华，并逐步开展湖泊生态系统的修

\footnotetext{
* 2007-04-04 收稿; 2007-06-11 收修改稿. 杨东妹, 女, 1981 年生, 硕士; E-mail: dmyang@niglas.ac.cn.

** 通讯作者; E-mail: qlwu@niglas.ac.cn.
} 
复, 从而缓解这一环境危害已经成为潜在的对策之一 ${ }^{[2]}$. 生物调控的重要内容之一是通过对食浮游动物鱼 类的调节来增加食浮游藻类动物的个体大小和密度及其对浮游藻类的牧食压力，提高水体透明度，且有 可能为沉水植物的生长提供条件 ${ }^{[3]}$. 直接利用滤食性水生生物控制浮游藻类水华也获得一些结果, 如在 我国东湖鲢、鳙鱼的养殖被认为是东湖蓝藻水华消失的主要因素 ${ }^{[4]}$; Hosper 和 Reeders 利用斑马贻贝 (Dreissena polymorpha) 在荷兰的一些湖泊中开展调控实验，也取得了较好的控藻效果 ${ }^{[5-6]}$; 河蚬种群的定 居和扩展被认为是美国哈德逊(Hudson)河中浮游藻类的减少和群落结构改变的主要因素 ${ }^{[7]}$. 背角无齿蚌 是我国分布广泛的经济淡水贝类之一, 目前国内已经有利用背角无齿蚌等淡水双壳类来开展富营养化水 体的环境治理和生态修复, 但是其对浮游藻类的下行控制效应及其机理尚不清楚.

本项研究的目的在于利用模拟的微型生态系统方法来分析背角无齿蚌的高强度滤食对微型生态系统 水柱中氮、磷等营养盐浓度和浮游澡类群落结构的影响, 评估利用背角无齿蚌调控藻类水华, 尤其是蓝藻水 华和改善水质的可行性, 探索其中的生态学机理, 为我国湖泊等富营养化水体的治理提供一些科学依据.

\section{1 材料与方法}

\section{1 微型生态系统的建立}

用体积为 $110 \mathrm{~L}$ 的白色聚乙烯塑料桶 (高 $100 \mathrm{~cm}$ 、底部直径约 $30 \mathrm{~cm}$ 、上部直径约 $45 \mathrm{~cm}$ ) 建立微型生态 系统, 分为实验组和空白对照组, 实验组和空白对照组均设置 3 个重复. 微型生态系统的水体积为 $100 \mathrm{~L}$, 水深为 $80 \mathrm{~cm}$ 左右. 实验水样取自滇池, 其基本的理化环境条件: 总磷 $(\mathrm{TP}) 0.265 \mathrm{mg} / \mathrm{L}$; 总氮 (TN) $3.321 \mathrm{mg} / \mathrm{L}$; 总溶解性磷 $(\mathrm{TDP}) 0.058 \mathrm{mg} / \mathrm{L}$; 总溶解性氮 $(\mathrm{TDN}) 0.865 \mathrm{mg} / \mathrm{L}$; 溶解活性磷 $\left(\mathrm{PO}_{4}{ }^{3-}-\mathrm{P}\right) 0.029 \mathrm{mg} / \mathrm{L}$; 藻类生物量 $7.14 \mathrm{mg} / \mathrm{L}$. 在塑料桶的底部放少量的经过自来水冲洗干净的黄沙, 厚度不超过 $1.0 \mathrm{~cm}$. 实验组各养殖 $1-2$ 只个体健康的背角无齿蚌(从滇池附近池䛸随机选择，总体重 $230245 \mathrm{~g}$ ), 用网目为 $2.8 \mathrm{~cm}$ 左右的尼龙线网 将蚌吊养在水面下 $50 \mathrm{~cm}$ 左右, 并置于水桶的中间位置; 空白组也吊养同样数量的空的尼龙网, 保证吊养 设施对系统影响的均等.

为尽量模拟自然状态下的环境状况，整个实验均在室外进行，根据连续观测，实验期间的水温为 $14.7-24.3^{\circ} \mathrm{C}$, 各微型实验生态系统的水温一致. 实验期间(2001 年 6 月 23 日-2001 年 8 月 1 日)的昆明地 区处于雨季, 降水略微大于蒸发量, 因此整个实验系统的水量基本保持 $100 \mathrm{~L}$ 左右(偶遇到较强降水时, 将 其盖住，以免雨水过多而溢出). 实验期间同时利用洗净的容积为 $3 \mathrm{~L}$ 左右的搪瓷缸(缸口面积 $150 \mathrm{~cm}^{2}$ 左右) 收集降水, 并测定降水中(包括因降尘带来的氮、磷含量)的总氮和总磷含量.

\section{2 样品的采集与分析}

对微型生态系统的营养物含量、水质和浮游藻类每周定期观测一次. 利用内径为 $5 \mathrm{~mm}$ 的洁净乳胶管 将水样从水面下 $20 \mathrm{~cm}$ 虹吸取出, 每次 $200 \mathrm{ml}$ 左右, 并立即测定水柱中的总磷、总氮、总溶解态磷、总溶 解态氮、正磷酸盐、叶绿素 $\mathrm{a}$ 和 $400 \mathrm{~nm}$ 处的吸光值, 总磷和总溶解态磷的测定采用硫酸消解-钼蓝比色 法; 正磷酸盐的测定采用钿蓝比色法; 总氮和溶解性总氮的分析采用硫酸消解-纳氏比色法, 悬浮态总磷 $=$ 总磷 - 溶解性总磷; 悬浮态总氮 $=$ 总氮 - 总溶解态氮, $0.45 \mu \mathrm{m}$ 醋酸纤维滤膜过滤的水样中所含的总氮磷为 溶解性总磷和总氮, 具体分析方法见湖泊富营养化调查方法 ${ }^{[8]}$. 同样方法取水样 $50 \mathrm{ml}$, 加人 $1.5 \%$ 鲁哥氏 液固定, 取 5-10ml 样品于藻类计数框内, 静置 $24 \mathrm{~h}$, 去处上清液, 利用德国产 Zeiss 倒置显微镜, 采用镜 检和视野计数法分析计数框内的浮游藻类，藻类只鉴别到属 ${ }^{[9]}$, 浮游藻类的生物量通过细胞体积换算而 得 $\left(10^{9} \mu \mathrm{m}^{3}\right.$ 细胞体积相当于 $1 \mathrm{mg}$ 生物量). 实验结束时, 测定沉积物中总氮和总磷含量 ${ }^{[8]}$.

\section{3 数据处理与统计分析}

One way ANOVA 分析实验组与对照组之间的差异显著与否, $t$-test 比较试验起始和结束时的沉积物 中营养盐含量, SigmaStat 软件进行统计分析.

\section{2 实验结果与分析}

\section{1 不同形态磷的变化}

背角无齿蚌对微型生态系统中总磷的影响不显著(空白组总平均 $=0.123 \mathrm{mg} / \mathrm{L}$, 实验组总平均 $=0.130$ 
$\mathrm{mg} / \mathrm{L}$, One way ANOVA 检验, $P=0.570$ ). 实验组与对照组的总溶解性磷含量差异显著(空白组总平均 $=0.046 \mathrm{mg} / \mathrm{L}$, 实验组总平均 $=0.066 \mathrm{mg} / \mathrm{L}$, One way ANOVA 检验, $P=0.020$ ). 背角无齿蚌的高密度放养对微 型生态系统中的溶解活性磷和总悬浮态磷的有一定影响, 但不显著 (空白组总溶解活性磷 $=0.019 \mathrm{mg} / \mathrm{L}$, 实 验组总活性磷 $=0.011 \mathrm{mg} / \mathrm{L}$, One way ANOVA 检验, $P=0.303$; 空白组总悬浮态磷 $=0.077 \mathrm{mg} / \mathrm{L}$, 实验组总悬 浮态磷 $=0.0644 \mathrm{mg} / \mathrm{L}$, One way ANOVA 检验, $P=0.408$ ) (图 1).

但是实验组与对照组之间的差别在每一次采样时并不一致，显示微型生态系统中的营养物水平波动 较大. 例如总磷在第 38 天时差异显著 $(t$-test, $P=0.014)$; 从实验开始到结束实验组与空白组之间的总溶解 性磷差异渐趋显著(图 1), 显示随着实验的继续, 背角无齿蚌可以显著增加水柱中的溶解性磷的含量.
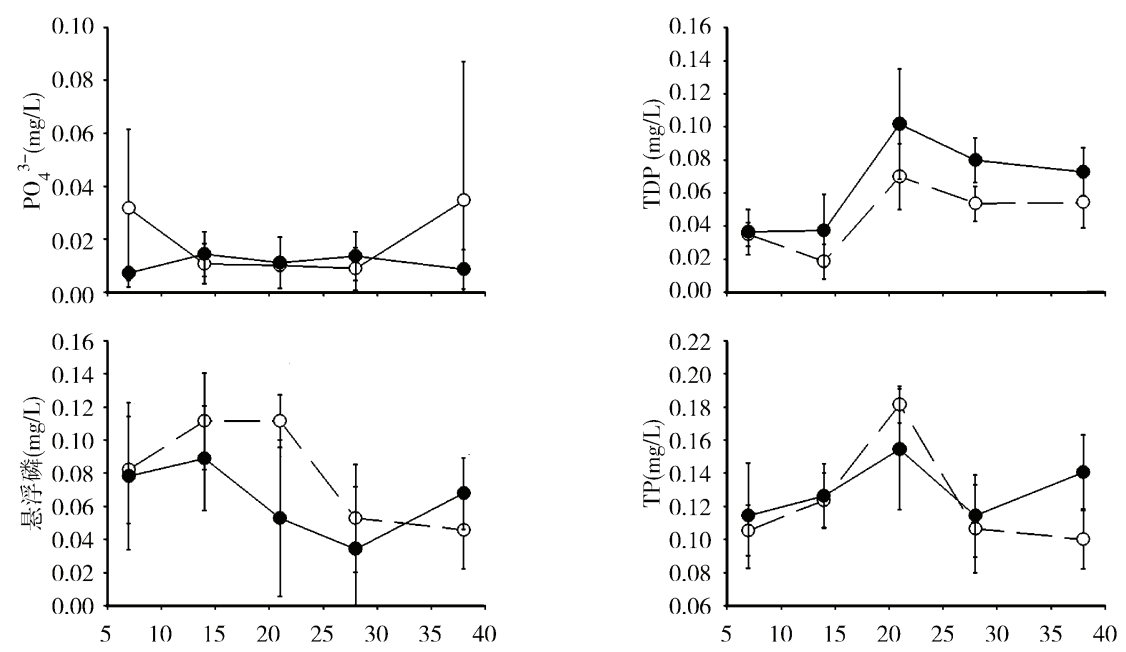

时间(d)

图 1 处理组 $(\bullet$ 与对照组 $(0)$ 微型生态系统中不同形态磷变化的比较

Fig.1 Dynamic of concentration of different phosphorus species between the treatment

$(\bullet)$ and the control (०) microcosms

\section{2 不同形态氮的变化}

背角无齿蚌的高密度养殖对微型生态系统中的总氮影响不显著(图 2)(空白组总平均值 $=2.445 \mathrm{mg} / \mathrm{L}$, 实
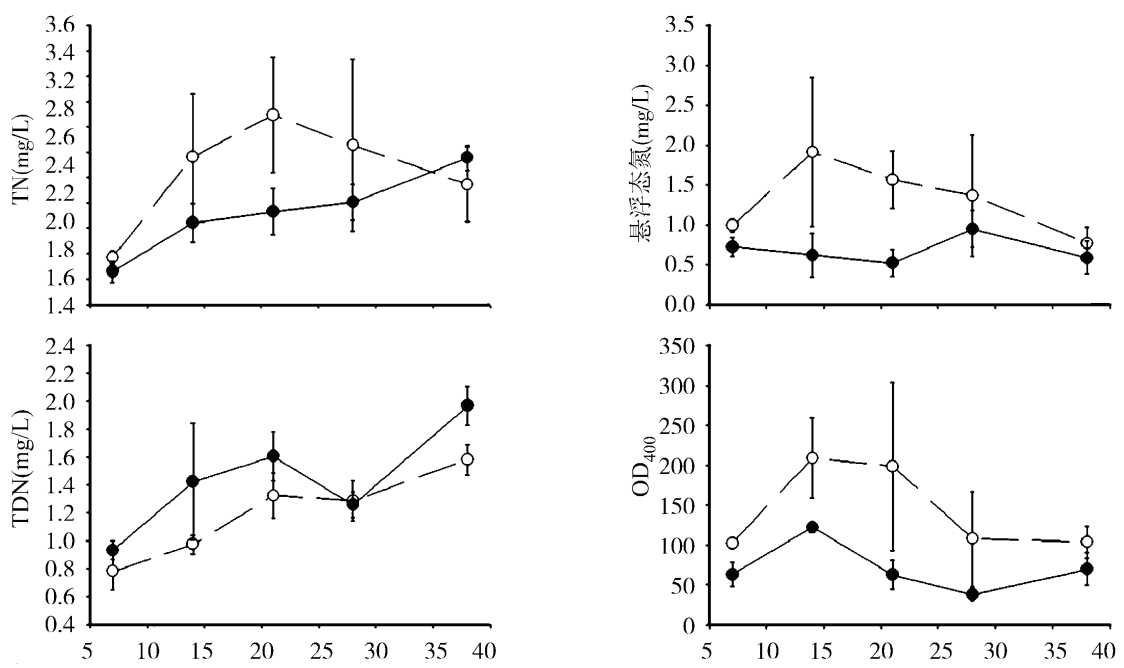

时间(d)

图 2 处理组 $\left(\bullet\right.$ 与对照组 $(\circ)$ 微型生态系统中不同形态氮以及 $\mathrm{OD}_{400}$ 变化的比较

Fig.2 Dynamic of concentration of different nitrogen species and $\mathrm{OD}_{400}$ between the treatment $(\bullet)$ and the control $(\circ)$ microcosm 
验组总平均值 $=2.118 \mathrm{mg} / \mathrm{L}$, One way ANOVA 检验, $P=0.126)$, 但是这种高密度的养殖显著地降低了微型生 态系统水柱中的悬浮态氮的含量(实验组总平均值 $=0.681 \mathrm{mg} / \mathrm{L}$, 空白组总平均值 $=1.255 \mathrm{mg} / \mathrm{L}$, One way ANOVA 检验, $P=0.033)$; 增加了水柱中溶解态氮的含 量 ( 空白组平均值 $=1.190 \mathrm{mg} / \mathrm{L}$, 实验组平均值 $=1.438 \mathrm{mg} / \mathrm{L}$, One way ANOVA 检验, $P=0.044)$. 实验组 透明度明显好于对照组.

\section{3 沉积物中营养物含量比较及降水中氮磷含量}

实验结束后的沉积物分析结果表明, 实验组与对 照组之间的沉积物总氮和总磷含量没有显著变化(实 验组总氮平均值为 $67 \mathrm{mg} / \mathrm{kg}$; 空白组总氮平均值为 $73 \mathrm{mg} / \mathrm{kg}$; $t$-test, $P>0.05$. 实验组总磷平均值为 $11 \mathrm{mg} / \mathrm{kg}$; 空白组总磷平均值为 $13 \mathrm{mg} / \mathrm{kg} ; t$-test, $P>0.05)$. 虽然没 有具体测定实验期间的降雨量, 但是实验期间降水中 (含降尘)的总氮和总磷含量极其有限, 每 $200 \mathrm{~cm}^{2}$ 降水 中的总磷和总氮含量分别只有 $0.04 \mathrm{mg}$ 和 $0.21 \mathrm{mg}$, 塑 料水桶(微型系统)的口部面积以 $1500 \mathrm{~cm}^{2}$ 计算, 进人 实验系统中的总磷和总氮分别为 $0.3 \mathrm{mg}$ 和 $1.575 \mathrm{mg}$, 不到微型生态系统中的总磷和总氮的 $2 \%$ 和 $1 \%$, 很明 显, 降水中的氮磷含量对微型生态系统实验的影响极 其有限.

\section{4 对浮游藻类生物量和密度的影响}

背角无齿蚌的高密度放养显著降低了微型生态系统 中浮游藻类的密度(图 3 one way ANOVA 检验, $P=0.011$ ) 和生物量(图 4 one way ANOVA 检验, $P=0.039$ ), 例如 试验初期的藻类密度和生物量分别为 $1.6 \times 10^{8} \mathrm{cells} / \mathrm{L}$ 和 $7.14 \mathrm{mg} / \mathrm{L}$, 实验结束时的空白组浮游藻类密度和生 物量分别为 $2.94 \times 10^{7}$ cells $/ \mathrm{L}$ 和 $4.187 \mathrm{mg} / \mathrm{L}$, 而处理组 的浮游藻类密度和生物量却分别只有 $2.6 \times 10^{6} \mathrm{cells} / \mathrm{L}$ 和 $0.215 \mathrm{mg} / \mathrm{L}$.

\section{5 对浮游藻类群落结构的影响}

在分析主要藻类属种的变化后发现(图 4), 空白组微 囊藻(Microcystis sp.)生物量在实验开始后即减少, 而 同属于蓝藻门的颤藻(Planktothrix sp.)、水华束丝藻 (Aphanizomenon flos-aquae sp.) 和项圈藻(Anabaenopsis $\mathrm{sp}$.) 则在试验的前 $30 \mathrm{~d}$ 左右不仅没有减少, 相反还略 有增加, 只是在实验结束时其生物量和密度显著减 少. 与此相对应, 处理组的这四种优势蓝藻受背角 无齿蚌的滤食影响, 生物量迅速下降, 并一直维持在 较低的水平上. 空白组绿藻门的鼓藻(Cosmarium sp.) 和四角藻(Tetraedron $\mathrm{sp}$.) 及栅列藻(Scendesmus spp.)生 物量均有所增加, 实验结束时分别为 3.472、0.3328 和 $0.2432 \mathrm{mg} / \mathrm{L}$; 处理组的鼓藻生物量也有所增加, 但是绝

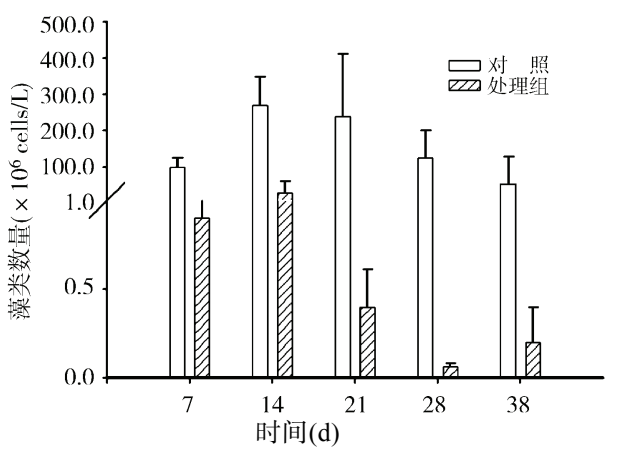

图 3 处理组与对照组微型生态系统中浮游藻类数量变化 Fig.3 Phytoplankton abundance in the treatment and the control microcosms
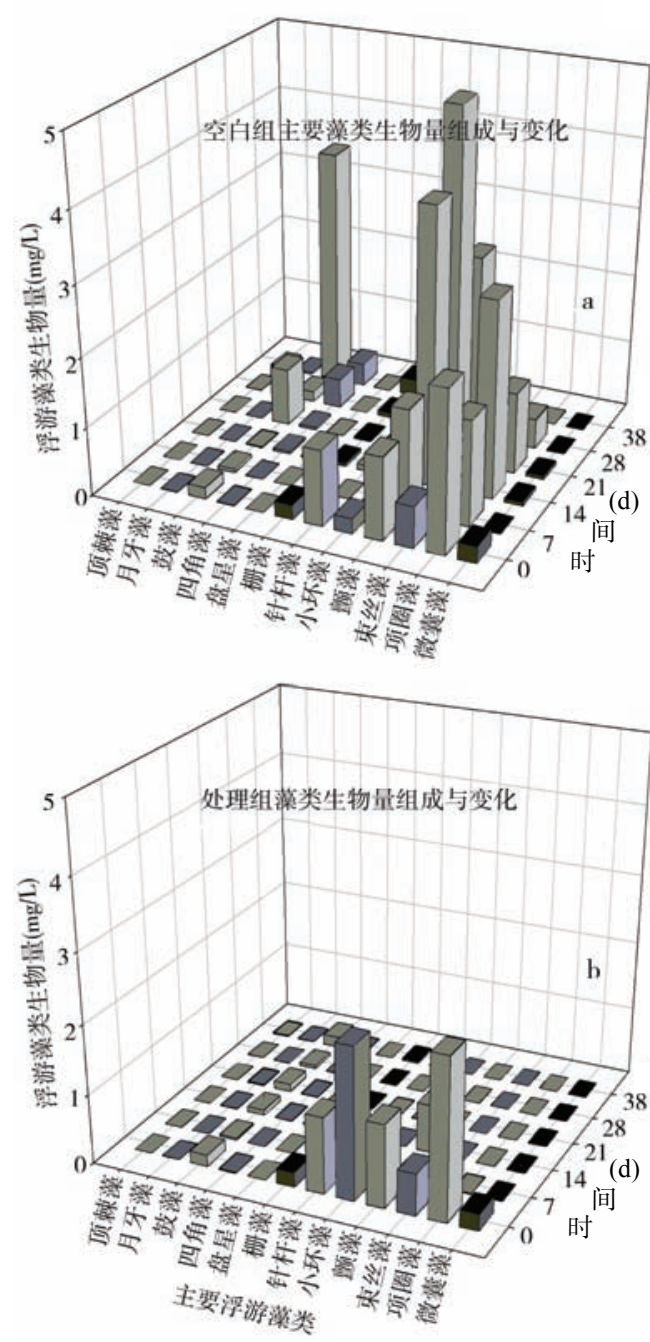

图 4 对照组(a)与处理组(b)微型生态 系统中浮游藻类组成变化

Fig.4 Succession of phytoplankton community between the control (a) and the treatment (b) microcosm 
对生物量比较低, 实验结束时的生物量只有 $0.1508 \mathrm{mg} / \mathrm{L}$, 而其它较常见的绿藻如盘星藻(Pediastrum $\mathrm{spp}$.)、月 牙藻 (Selenastrum sp.) 和顶棘藻 (Chodatella sp.)的生物量变化不大; 硅藻门中较常见的小环藻 (Cyclotella sp.)和针杆藻 (Synedra sp.) 在空白组和处理组中均呈现出下降的趋势. 将不同藻类门的浮游藻类所占比例 进行比较后发现, 在试验的前 $30 \mathrm{~d}$ 左右背角无齿蚌的滤食明显减少了微型生态系统中浮游蓝藻所占比例, 增加了硅藻门㩰类和绿藻所占的比例, 对隐藻(Cryptomonas sp.)等隐藻门藻类所占比例的影响不明显. 而 裸藻(Euglena sp.)属于偶见种, 影响也不明显.

\section{3 讨论}

\section{1 对微型生态系统营养水平的影响}

本实验设计初始时的蚌的滤食速率约每小时 $500 \mathrm{ml} / \mathrm{kg}$ 左右(根据蚌的个体大小及水体中的悬浮物质 量估算 ${ }^{[9]}$, 生物量为 $2.3 \mathrm{~kg} / \mathrm{m}^{3}$, 即 $7-10 \mathrm{~d}$ 时间微型生态系统中的水要被背角无齿蚌滤食一遍. 在这样的高 强度滤食情况下, 水体中的营养物质及其形态发生了明显变化, 特别是溶解态的氮、磷浓度显著增加, 在 实验后期, 即使在溶解态氮、磷浓度较高和正磷酸盐浓度较低的情况下, 总的氮磷浓度没有显著变化(图 1 , 图 2), 显示在浮游藻类之外存在其它的悬浮体, 实际上在浮游藻类减少后, 水体中能抵抗贝类滤食的 丝状藻类-丝藻等得以利用营养盐, 从而逐渐生长.

一些研究结果认为贝类和鲢鱼等滤食性生物的滤食能够促进水体中悬浮物质的沉降, 增加表层沉积 物中的氮、磷含量 ${ }^{[10-13]}$, 本项实验期间, 这种现象并不明显, 这或许存在以下几个原因: (1)背角无齿蛙的 高强度滤食加快了系统内部的营养循环, 促进氮磷营养物质的再生, 使得较多营养物质回归到水柱中, 从而减少了营养物的沉积量; (2)藻类经过蚌的分解后会导致水体中可溶性有机质增加，进而会导致水体 中细菌等微生物类群的迅速增殖, 从而加速水体中氮磷的循环; (3)微型试验生态系统体积较小, 表层沉 积物较容易悬浮回归到水柱中. 淡水生态系统中的水柱营养物质浓度与系统内部营养循环密切相关, 对 试验系统中各营养盐指标与浮游藻类密度及生物量进行相关分析, 没有贝类滤食时, 浮游藻类的密度和 生物量与总氮、总磷、悬浮态氮和悬浮态磷(表 1)显著正相关, 具有明显的上行影响; 而有贝类滤时后, 生 态系统的结构发生了改变, 浮游藻类与氮磷营养盐之间(总磷、总氮)具有一定程度的负相关关系(表 2), 存 在营养级联假说中预见的下行效应 ${ }^{[14]}$. Starling 利用中型生态系统研究在较高生物量条件下 $\left(41 \mathrm{~g} / \mathrm{m}^{3}\right)$ 鲢鱼 滤食对水体富营养化的影响, 结果显示可以降低水体中的叶绿素含量, 但是对总磷、总氮、溶解性氮、 磷和悬浮态氮、磷以及正磷酸盐含量均没有显著影响 ${ }^{[12]}$. Hosper 等指出, 当贝类的滤食强度增加到一定 程度并超过藻类生长潜力时, 就可以在营养水平较高的情况下抑制浮游藻类的生长 ${ }^{[5]}$.

表 1 空白组各因素之间的自相关分析 ${ }^{*}$

Tab.1 Correlation coefficients among different factors in the control

\begin{tabular}{llllllllll}
\hline & 藻密度 & $\mathrm{DP}$ & $\mathrm{DN}$ & $\mathrm{TP}$ & $\mathrm{TN}$ & $\mathrm{PO}_{4}{ }^{3-}-\mathrm{P}$ & $400 \mathrm{~nm}$ & 悬浮氮 & 悬浮磷 \\
\hline 藻量 & $0.772^{* *}$ & 0.0384 & 0.341 & $0.609^{* *}$ & $0.795^{* *}$ & -0.120 & $0.962^{* *}$ & $0.555^{* *}$ & $0.811^{* *}$ \\
藻密度 & 1 & -0.062 & -0.097 & $0.529^{* *}$ & $0.595^{* *}$ & -0.318 & $0.855^{* *}$ & $0.564^{* *}$ & $0.732^{* *}$ \\
$\mathrm{DP}$ & & 1 & 0.368 & 0.404 & 0.367 & 0.196 & 0.040 & -0.244 & -0.086 \\
$\mathrm{DN}$ & & & 1 & 0.146 & $0.523^{* *}$ & -0.010 & 0.188 & -0.101 & 0.182 \\
$\mathrm{TP}$ & & & & 1 & $0.628^{* *}$ & -0.157 & $0.608^{* *}$ & $0.738^{* *}$ & $0.561^{* *}$ \\
$\mathrm{TN}$ & & & & 1 & -0.184 & $0.746^{* *}$ & 0.376 & $0.742^{* *}$ \\
$\mathrm{PO}_{4}{ }^{3-}-\mathrm{P}$ & & & & & & 1 & -0.17 & -0.302 & -0.274 \\
$400 \mathrm{~nm}$ & & & & & & & 1 & $0.576^{* *}$ & $0.795^{* *}$ \\
悬浮氮 & & & & & & & & 1 & $0.680^{* *}$ \\
悬浮磷 & & & & & & & & & 1 \\
\hline
\end{tabular}

*表中为相关系数, $* *$ 指相关关系显著 $(n=18,5 \%$ 显著性水平 $)$.

通过本项实验可以得出以下初步结论，在没有或者极少外来氮磷污染负荷的情况下，利用背角无齿 
蚌的滤食来控制浮游藻类、提高水体透明度是可行的, 但是对水柱中总的营养物浓度并没有明显影响, 而且随着时间的延续, 附着藻类和丝状藻类大量生长, 显示背角无齿蚌的的滤食并不能有效减缓微型生 态系统中的富营养化水平, 三角帆蚌(Hyriopsis cumingii Lea)对富营养化水体悬浮物消除的时效模型也表 明单一利用贝类控制水体富营养化的可能性较低 ${ }^{[18]}$.

\section{表 2 实验组各因素之间的自相关分析 ${ }^{*}$}

Tab.2 Correlation coefficients among different factors in the control

\begin{tabular}{llllllllll}
\hline & 藻密度 & $\mathrm{DP}$ & $\mathrm{DN}$ & $\mathrm{TP}$ & $\mathrm{TN}$ & $\mathrm{PO}_{4}{ }^{3-}-\mathrm{P}$ & $400 \mathrm{~nm}$ & 悬浮氮 & 悬浮磷 \\
\hline 藻量 & $0.861^{* *}$ & -0.252 & 0.0165 & -0.123 & -0.01 & 0.276 & $0.648^{* *}$ & 0.121 & -0.037 \\
藻密度 & 1 & -0.269 & -0.249 & -0.238 & -0.216 & 0.065 & $0.592^{* *}$ & 0.014 & 0.133 \\
$\mathrm{DP}$ & & 1 & 0.347 & 0.219 & 0.445 & 0.161 & -0.423 & $-0.517^{* *}$ & 0.011 \\
$\mathrm{DN}$ & & & 1 & 0.439 & $0.817^{* *}$ & 0.289 & 0.09 & 0.142 & $-0.607^{* *}$ \\
$\mathrm{TP}$ & & & & 1 & 0.489 & -0.217 & 0.226 & 0.658 & -0.087 \\
$\mathrm{TN}$ & & & & & 1 & 0.094 & 0.009 & 0.007 & -0.375 \\
$\mathrm{PO}_{4}{ }_{4}{ }^{-}-\mathrm{P}$ & & & & & & 1 & 0.0748 & -0.205 & -0.372 \\
$400 \mathrm{~nm}$ & & & & & & & 1 & $0.528^{* *}$ & -0.144 \\
悬浮氮 & & & & & & & & 1 & -0.237 \\
悬浮磷 & & & & & & & & & 1 \\
\hline
\end{tabular}

*表中为相关系数, **指相关关系显著 $(n=18,5 \%$ 显著性水平).

\section{2 对浮游藻类影响分析}

淡水双壳类对浮游藻类群落结构的间接影响包括以下几个方面：(1)改变营养盐和光照等条件，从而 使得部分适合此条件的藻类成为优势群体; (2)以一定的滤食速率来去除一些生长速度较慢的藻类, 而使 得生长较快的藻类成为优势; (3)由于背角无齿蚌属于底栖生物, 它们从水柱中摄食处于下层的非飘浮性 藻类, 从而可能导致一些飘浮性藻类成为多数. 背角无齿蚌的滤食活动对浮游藻类的直接影响包括以下 几个方面: (1)选择性的滤食; (2)选择性摄取; (3)选择性消化利用. 这些直接和间接的机制即可以单独也可 以同时在生态系统水平上对浮游藻类群落结构产生影响, 改变浮游藻类的种类组成, 本项实验即在微型 生态系统水平上阐释背角无齿蚌的高密度滤食对浮游藻类产生的综合影响.

很明显背角无齿蚌的高密度滤食可以有效地降低浮游藻类总的密度和生物量, 并使其维持在较低的 水平上. 尽管相关的研究表明贝类等滤食性生物的滤食活动可以加快水体中的营养循环 ${ }^{[16]}$, 从而可能为 浮游藻类的生长提供一定的补偿, 但是当淡水双壳类的滤食强度增加到一定程度并超过藻类生长潜力时, 就可以在营养水平较高的情况下抑制浮游藻类的生长 ${ }^{[14]}$.

背角无齿蚌对微型生态系统中几乎对所有的浮游藻类都具有控制作用, 这验证了前期研究所揭示的 无齿蚌对浮游藻类的摄食选择性较低这一现象 ${ }^{[9]}$, 但是在生态系统水平上其对浮游藻类群落结构仍产生 了一定程度的间接影响, 虽然所有浮游藻类的生物量均很低, 但是蓝藻门藻类所占比例明显下降, 而绿 藻门的单细胞藻类如鼓藻等所占比例显著增加，这与阮景荣等利用微型生态系统实验分析鲢鲜鱼的滤食 对浮游藻类群落的影响相似 ${ }^{[17]}$, 表明在高密度的滤食之下, 尽管藻类密度和生物量减少, 但是并不代表 水体的富营养化水平有明显下降. 而微囊藻等的迅速减少除了因为背角无齿蚌的滤食外，可能主要源于 它不适合于在微型生态系统中生长, 空白组的微囊藻密度在实验开始后的几天内也显著减少并且一直很 低这一现象可以佐证上述观点(图 4).

\section{4 参考文献}

[1] Dokulil MT, Teubner K. Cyanobacterial dominance in lakes. Hydrobiologia, 2000, 438: 1-12.

[2] Gulati RD, Lammens EHRR, Meijer ML (eds). Biomanipulation tool for water management. Belgium: Kluwer Academic Publishers, 1990. 
[3] Shapiro J. Biomanipulation-The next phase-making it stable. Hydrobiologia, 1990, 200: 13-27.

[4] 谢 平主编. 鲢、鳙鱼与藻类水华控制. 北京: 科学出版社, 2003.

[5] Hosper SH. Biomanipulation, new perspective for restoring shallow eutrophic lakes in the Netherlands. Hydrobiology Bulletin, 1989, 23(1): 5-10.

[6] Reeders HH, Bij De Vaate A, Slim FJ. The filtration rate of Dreissena polymorpha (Bivalvia) in three Dutch lakes with reference to biological water quality management. Freshwater Biology, 1989, 22(1): 133-141.

[7] Caraco NF, Cole JJ, Raymond PA et al. Zebra mussel invasion in a large, turbid river: Phytoplankton response to increased grazing. Ecology, 1997, 78(2): 588-602.

[8] 金相灿, 屠清瑛主编. 湖泊富营养化调查规范. 北京: 中国环境科学出版社, 1990.

[9] 吴庆龙, 陈宇炜, 刘正文. 背角无齿蚌对浮游藻类的滤食选择性与滤水率研究. 应用生态学报, 2005, 16(12): 2423-2427.

[10] 尹 宇. 皱纹冠蚌和三角帆蚌的代谢及其与环境的关系(初步研究)[学位论文]. 南京: 中国科学院南京地理与湖泊研究所, 1988.

[11] Reeders HH, Bij De Vaate A. Zebra mussels (Dreissena polymorphia): a new perspective for water quality management. Hydrobiologia, 1990, 200(1): 437-450.

[12] Starling FLDRM. Control of eutrophication by silver carp (Hypophthalmichthys molitrix) in the tropical Paranoa Reservoir (Brasilia, Brazil): a mesocosm experiment. Hydrobiologia, 1993, 257(3): 143-152.

[13] Tenore KR, Dunstan WM. Comparison of feeding and bio-deposition of three bivalves at different food levels. Marine Biology, 1973, 21(3): 190-195.

[14] Carpenter SR, Kitchell JF, Hodgson JR. Cascading trophic interactions and lake productivity. Bioscience, 1985, 35: 634-639.

[15] Bastviken DTE, Caraco NF, Cole JJ. Experimental measurements of zebra mussel (Dreissena polymorpha) impacts on phytoplankton community composition. Freshwater Biology, 1998, 39(2): 375-386.

[16] 董双林. 鲢鱼的放养对水质影响的研究进展. 生态学杂志, 1994, 13(2): 66-68.

[17] 阮景荣, 戎克文, 王少梅. 微型生态系统中鲢䲠鱼下行影响的研究——营养物水平. 湖泊科学, 1995, 7(4): 334-340.

[18] 费志良, 廖 馨, 赵沐子等. 三角帆蚌(Hyriopsis cumingii Lea)对富营养化水体悬浮物消除的时效模型. 南京大学学报(自 然科学版), 2005, 41(6): 634-638. 